in the care of crippled children, that fresh air and sunlight form an essential basis for treatment. We can safely prophesy that the time will soon come when the town hospital for children will be looked upon as an anachronism. These country hospitals are responsible for the treatment, education, and training of cripples drawn from large adjacent areas. Around the hospital are grouped after-care clinics to which children are brought after being evacuated from the hospital beds, while other cases are seen which require admission for operation or prolonged treatment. These clinics, with their nurses, are periodically visited by surgeons from the hospital, and in this way continuity of treatment is assured and relapse prevented. This network of clinics has resulted in a marked diminution of those gross deformities which are caused by neglect. We hope before very long to see this scheme functioning over all parts of the British Isles.

Despite all that can be done for children by preventive methods we can never hope to be without the cripple problem. The menace of transport is ever increasing, while there is but little corresponding expansion in hospital accommodation. The adult industrial cripple has been neglected in England until lately. Other countries, notably America, are alive to the importance of this problem. There, schemes for rehabilitation are quickly developing. The Federal Board of the United States shows that, up to 1926, 24,000 disabled persons had been restored to work at an average cost of $£ 50$ per head. In America alone $\mathbf{8 4 , 0 0 0}$ are disabled vocationally every year. This great work relieves the State of a heavy financial burden, apart from the moral aspect of the problem. It is essentially humane and economical.

While we are all deeply interested in the work of our own nation we are very apt to be ignorant of the activities of our neighbours. Nothing can prove of greater value than international meetings in familiarizing us with the activities in which we are interested all the world over. A too rigid nationalism has its grave defects. We are all the better for early access to the literature and work of the several countries, and this is especially so in the cause of the cripple. Brackett of Boston has suggested that there should be a central bureau of information at Geneva, attached to the League of Nations. It should act as a centre for collecting and distributing information regarding cripples in all civilized countries. It should cover preventive treatment and training, and should include methods of dealing with those injured in industry. Such a source of information would be a great service to all of us. It would unite the nations in a common quest.

\section{A CASE OF PITUITARY TUMOUR} BY $\cdot$

C. C. ELLIOTT, M.D., B.S.

SURGEON, SOMERSET HOSPITAL, CAPETOWN, AND LECTURER IN CLINICAL SURGERY, UNIVERSITY OF CAPETOWN AND

DAVID P. MARAIS, M.D., F.R.C.P.ED.

PHYSICIAN, SOMERSET HOSPITAL, CAPETOWN, AND LECTURER IN CLINICAL MEDICINE, UNIVERSITY OF CAPETOWN

The subject of this report is a professional man now $\mathbf{5 0}$ years of age. He was first seen about seven years ago by one of us (D. P. M.) in consultation with his family attendant. The particular interest in the case lies, in the first place, in the currious onset, and secondly, in the pathological cause, the removal of which eliminated in large part the original symptoms.

\section{Signs and Symptoms}

The earliest symptoms arose some twelve months prior to the consultation. The patient's partner had noticed a marked slacking-off in his work. Although he attended office punctually and regularly he accomplished very little real work, spending most of his time behind closed doors, writing voluminously, and destroying at the end of the day the results of all his labour. He took little interest in his profession, but when asked his opinion seemed as alert and as sound as usual. On rare occasions a letter missed destruction, and several were gradually collected. In one of these the patient styled himself a knight, and wrote about the millions he was investing. The theme was usually suggested by a business letter or a consultation. Thus, following a consultation on mining matters, his subsequent letters dilated upon the millions paid by this mine, all earned by himself; after a professional conversation about shipping he wrote to his son, still a schoolboy, about his yacht, giving it the name of a liner previously discussed, and describing his wanderings across the Seven Seas. In other respects-in conversation, intelligence, and in conduct-he appeared to be his normal self.

When first examined the patient was a heavily built man, $71 \frac{1}{4}$ inches in height and weighing $203 \mathrm{lb}$., with large features and a strikingly pallid complexion. The facial characteristics were somewhat prominent supra-orbital ridges and malar eminences, and a heavy lower jaw ; there was also some puffiness below the eyes. The hands were large, and showed distinct thickening of the skin-a "solid oedema." The skin of the trunk was smooth and very pallid. There was general loss of hair, the pubic hair being scanty and resembling in its distribution that of the female. The penis was small, as were the testes, which were insensitive to pressure. The patient complained of loss of sexual desire and admitted impotence. Generally the trunk indicated the adipose appearance associated with a pituitary dystrophy. Other symptoms -for example, headache, vomiting, etc.-were strikingly absent. The patient, in fact, had no complaints to make, and only admitted, rather shamefacedly, the indulgence of "day-dreams," as he called them, when he composed his lettens.

A systematic examination elicited the following facts. The cardio-vascular system showed little abnormality. Blood pressure was $130 / 80$; pulse rate was 70 . Examination of the heart revealed no enlargement or degenerative changes. The blood picture indicated a mild grade of anaemia-4,950,000 red cells per c.mm., and 78 per cent. haemoglobin. A census showed cells of normal size and staining capacity, and a slight relative lymphocytosis.

Occasionally, at irregular intervals, the urine contained a small amount of sugar and a trace of albumin (salicylsulphonic acid test). A glucose tolerance test gave fairly

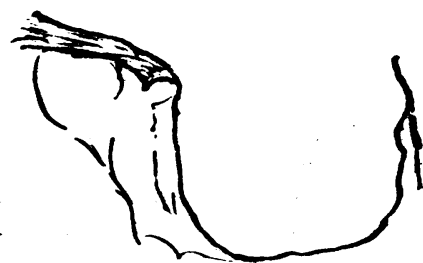

FIG. 1.-Tracing of sella turcica $(26 \times 25 \mathrm{~mm}$.).

normal values, fasting sugar in one test being $0.0665 \mathrm{mg}$. per cent. After $\mathbf{5 0}$ grams of glucose had been taken the percentages of sugar recorded half-hourly were: $\mathbf{0 . 0 9 1 5}$, $0.125,0.093,0.073,0.0592$, with a urine specific gravity of 1032 ; yet no sugar was excreted. A urea concentration test indicated 3.7 per cent. of urea after the first hour, and 4.1 per cent. after the second hour. The deposit contained no cells or casts, only an excess of phosphates being present. Examination of the eyes disclosed a restriction of the fields of vision. A full examination was made by Dr. A. W. Sichel, whose report is appended. An $x$-ray examination of the skull by Dr. van Rooyen indicated clearly a very much enlarged pituitary fossa measuring 26 by $25 \mathrm{~mm}$. (normal 13 by $8 \mathrm{~mm}$.) (Fig. 1). 
The diagnosis arrived at was that of a tumour or enlargement of the pituitary body causing increase in size of the sella turcica and pressure symptoms on the right optic chiasma affecting particularly the right optic tract. The patient was then placed in the hands of Dr. C. C. Elliott, who decided to operate.

\section{OpERATION}

On February 2nd, 1924, an osteoplastic flap was turned down over the right frontal region with its base external. The right lobe was elevated in its dura mater. After identifying the lesser wing of the sphenoid, the optic nerve was traced. The dura mater over the sella was then opened, and a purplish tumour was seen. It was spooned out with a blunt spoon. The sella was deep. The flap was replaced without drainage. The patient was conscious the same evening.

\section{Progress Notes}

There was at first paresis of the right internal rectus, and partial ptosis of the right eyelid. The patient was blind in the right eye, but could see with the left. The paresis of the right rectus and eyelid soon improved. During the first few days he was restless and irritable, but rapidly became normal. The wound healed by first intention. On February 20th the patient could read with the left eye. In May he reported that he could do three hours' work a day, walk two miles, see clearly with the left eye, and that he had no " day-dreams."

Having examined him in January, 1925, Dr. Sichel reported that the vision of the left eye was better, although the fields were the same as before. The patient said he had "day-dreams" when he was pressed with work. The hair of the head was much thicker and more luxuriant. He was still impotent. He worked full time at his office. In the interval he had taken pituitary extract regularly. Drs. Marais and Kooy saw him and recommended mixed endocrines.

In $1927 \mathrm{Dr}$. Sichel reported that the vision was not so acute and that the fields were slightly more constricted. The patient still had occasional " day-dreams." The pubic hair had partly grown, not the axillary, but there was some hair on the arms and the hands. $\mathrm{He}$ had still no libido. He could perform all his work.

In 1930 the patient was examined at his home. $\mathrm{He}$ still managed his office, but had " day-dreams" when fatigued. There were no further changes in acuity of vision, nor any other symptoms.

\section{COMMENTARY}

We have reported this case, having followed it up for over six years after operation. We operated at the right side, because, though the field of vision was more open on that side, the onset of complete blindness was more advanced in that eye, and therefore operative injury to the right optic nerve would not have been so serious. The perimeter charts demonstrate how the field cleared on the other side. Apart from the curious fantasy symptoms, the patient has led a normal and useful life since the operation. Whether the mental symptoms are due to an endocrine defect we do not know.

\section{Professor Bartlett's Report}

Naked-eye examination of the pituitary tumour showed some fragments of soft friable tissue of a brownish colour. Microscopical examination revealed acinar and intra-acinar papillary, polygonal-celled carcinoma of anterior lobe of the pituitary gland. The cells forming the growth were epithelial, obviously arising from the acinar epithelium. The appearance was very atypical: the acini were much larger than normal, and some of them were dilated, but filled by intra-acinar papillary growth. The cells which filled the acini and covered the papillae were large and polygonal in shape. The nucleus was large, round, or oval ; their protoplasm was abundant, faintly eosinophile. and spongy or vacuolated. Cells containing haemotoxyphil granules were extremely rare, but a careful search revealed a few; these were large and occasionally multinucleate. One of the fragments showed colloid spaces of the pars intermedia; another showed tissues of the anterior lobe ; in each case there was invasion by growth. A small portion of brain tissue showed no invasion. Fragments of the capsule showed definite invasion. The growth was of a common " adenocarcinoma" type frequently reported in this situation. As usual, most of the cells were " chromophobic "that is, they did not show granules. The growth was therefore composed of those cells which proliferate in pregnancy. The benign type of this neoplasm is sometimes found after repeated pregnancies, and generally regresses spontaneously.

\section{DR. SiChEL'S RePort}

The patient was referred to me on January 24 th, 1924, by Dr. D. P. Marais for a report on the fundi and visual fields. There was a history of enlargement of sella turcica, as shown by $x$-ray examination, and symptoms of pituitary and thyroid involvement. The patient stated that he had had diplopia since May, 1923, especially when reading.

Vision.-Right eye: with a correcting lens of $\mathbf{- 0 . 5 0}$ spherical and -0.50 cylindrical, axis 90 , fingers were seen at 1 metre. Left eye : with $-\mathbf{4 . 5 0}$ spherical and $\mathbf{- 0 . 5 0}$ cylindrical, axis 90 , his vision was $5 / 36$.

Pupils.-Equal in size, sluggish response to light both directly and consensually; no obvious response to convergence.

Fundi.-No definite pallor of discs. Examination complicated owing to presence of myopic coni and greyness of lamina cribrosa. No gross pathological changes in retina or choroid.

Fields.-No central scotoma for colours (Figs. 3 and 4). Central vision of right eye appears to be involved-that is, fixation object comes and goes. Tests for diplopia impossible owing to defective image perception in right eye.

Diagnosis.-Examination indicates pressure in direction of arrow (Fig. 2) involving crossed fibres from left eye

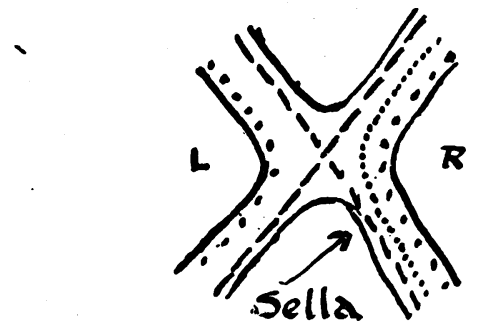

Fro. 2.-The arrow indicates site of pressure.

Crossed fibres: - - - - -

Uncrossed fibres: - ..........

Macular fibres:

and macular bundle from right eye : uncrossed fibres from right eye not implicated.

Progress Notes.-February 29th, 1924: First examination since operation. Right eye diverges and vision in it is nil (no perception of light). Vision left eve with correction $=5 / 18$ partly. Reads $J 1$ with difficulty. Fundi unchanged. See field (Fig. 5). March 5th: Rignt eye, ,vision nil. Left eye with correction $=5 / 12$ partly. Examination of left visual field by Elliott's scotometer shows sector of blind area extending to about 5 degrees from fixation point. January 5th, 1925: Right eye shows optic atrophy. Left fundus normal. Vision left eyje $=\mathbf{5} / 8$ partly. Right eye slightly divergent and has no power to converge. See field (Fig. 6). March 14th, 1927: No further complaint. Has never been able to do much extra reading since operation in spite of improved vision. Vision left eye with correction $=5 / 12$ partly and reads $\mathrm{J} 1$ with difficulty, having to make out words one by one. Right pupil reacts very slightly to direct light. Fifth nerves, as indicated by no loss of corneal sensibility, not involved. See field (Fig. 7). October 4th, 1928: Patient advised to return home; he has done more harm to himself by anxiety than can be explained by actual loss of vision. See field (Fig. 8). 


\section{0/300 (WHITE) \\ RIGHT.}

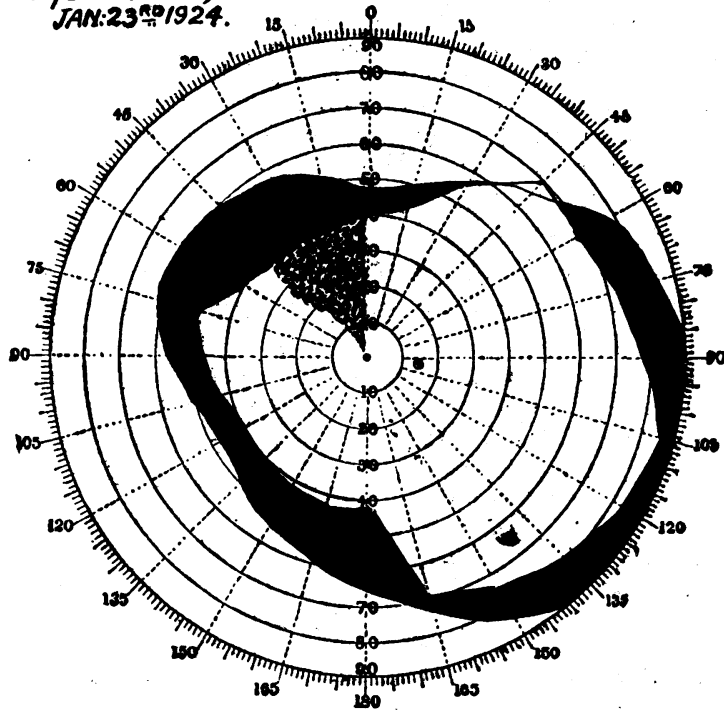

FIG. 3.

10/300(whete)

FED:29rN 1924

LEFT.

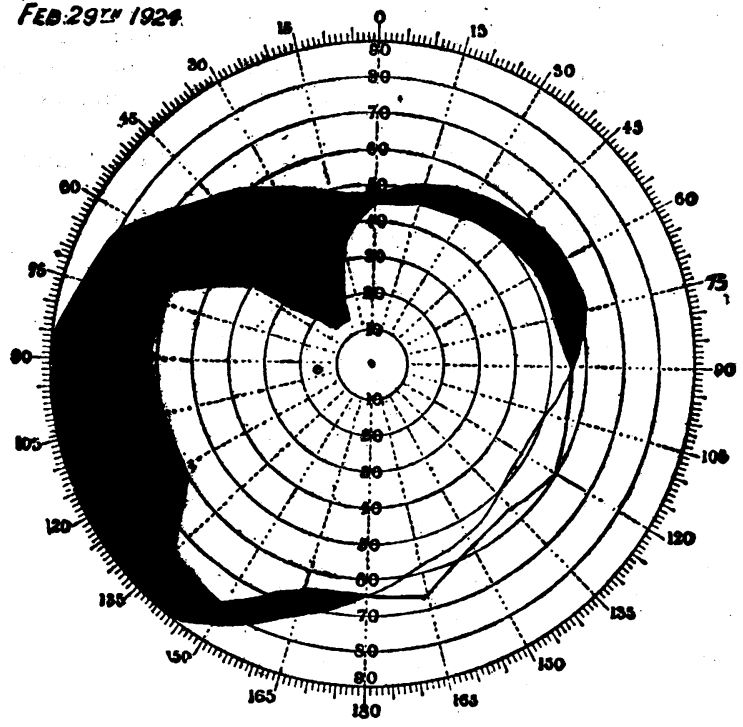

Fig. 5.

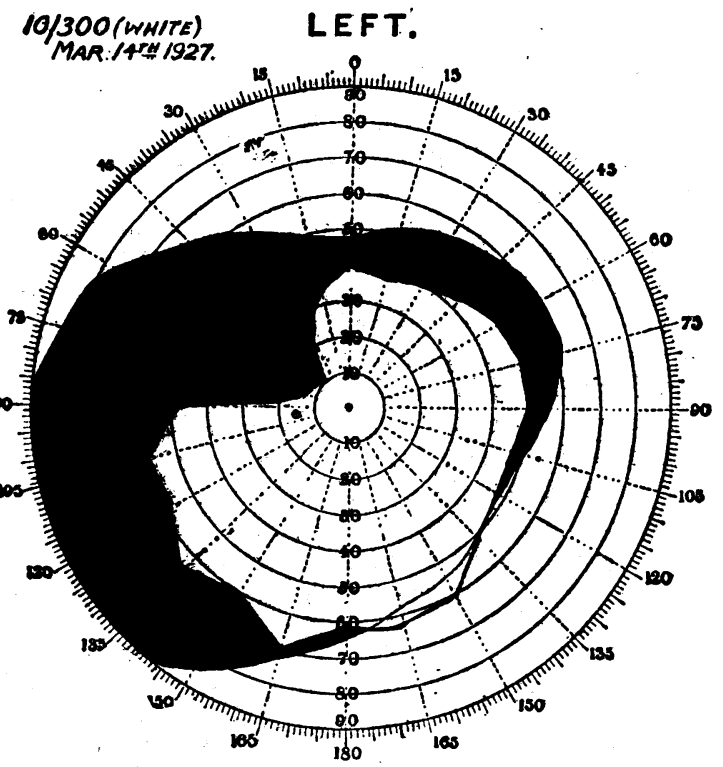

FIG. 7.
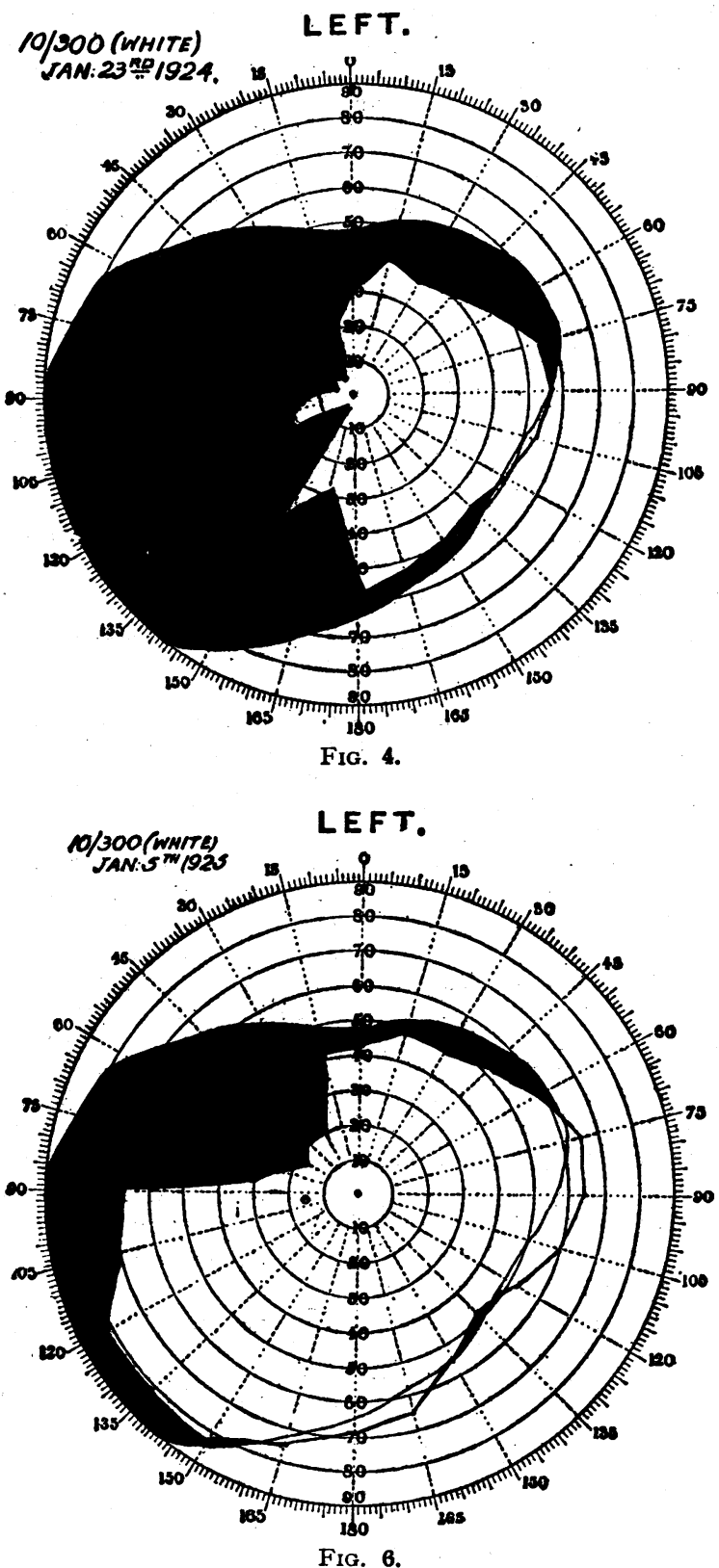

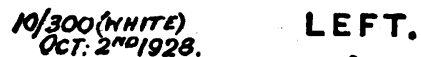

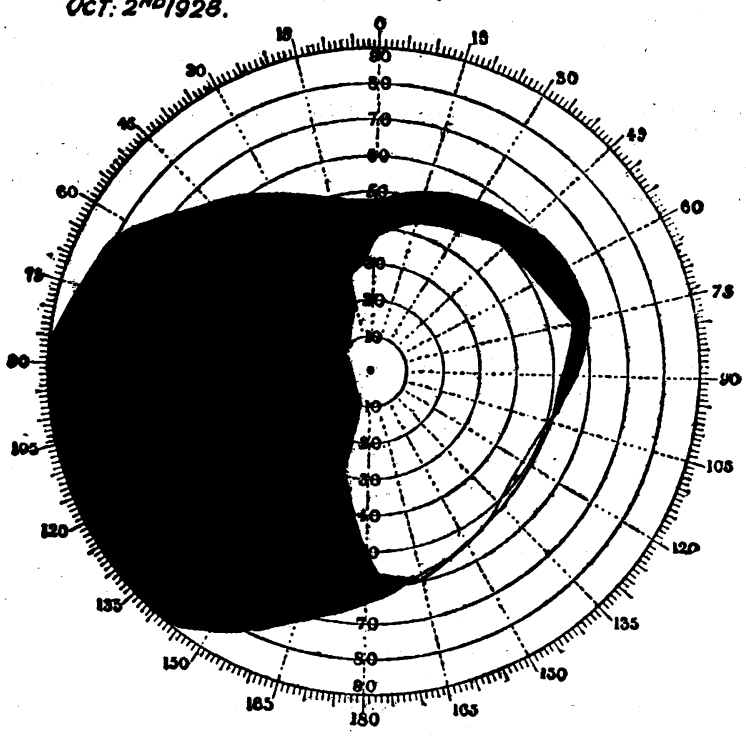

Fig. 8. 